
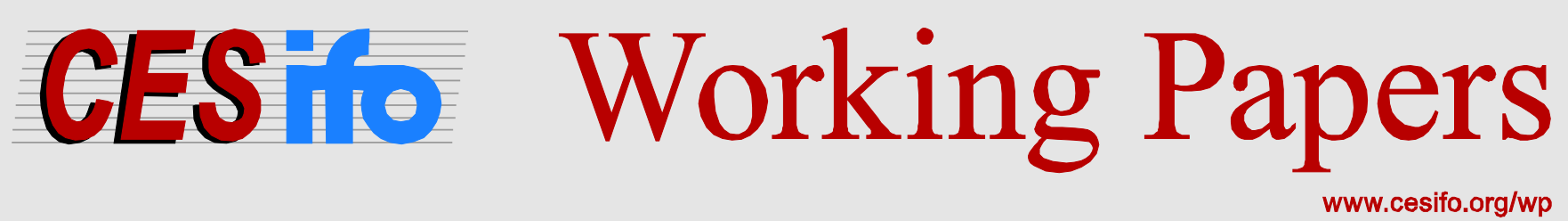

\title{
Political Connections, State Ownership and Productivity in China
}

\author{
Richard Harris \\ Nigar Hashimzade \\ Sai Ding
}

CESIFO WORKING PAPER NO. 6236

CATEGORY 11: INDUSTRIAL ORGANISATION

DECEMBER 2016
An electronic version of the paper may be downloaded
- from the SSRN website: Www.SSRN.com
- from the RePEc website: Www.RePEc.org
- from the CESifo website: www.CESifo-group.org/wp




\title{
Political Connections, State Ownership and Productivity in China
}

\begin{abstract}
Subordination of business to political influence has remains pervasive in China. We construct a Schumpeterian-type model of growth with managerial time allocation between productive activities and building up political connections. The model predicts the impact of different patterns of state ownership and/or political connectedness on firm productivity linked to a period of liberalization. We then investigate the relationship between political connections, state ownership, and total factor productivity (TFP) using firm-level data for China between 1998 and 2007. We find, consistent with the model, that the firms with the highest levels of TFP had low levels of political affiliation and/or state ownership.
\end{abstract}

JEL-Codes: D240, O140, O430.

Keywords: TFP, political connections, state ownership, China.

Richard Harris*

Department of Economics \& Finance

Durham University Business School Mill Hill Lane

United Kingdom - Durham DH1 3LB

r.i.d.harris@durham.ac.uk
Nigar Hashimzade

Department of Economics \& Finance

Durham University Business School

Mill Hill Lane

United Kingdom - Durham DH1 3LB

nigar.hasimzade@durham.ac.uk

\author{
Sai Ding \\ Department of Economics \\ Adam Smith Business School \\ University of Glasgow \\ United Kingdom - Glasgow G12 8QQ \\ Sai.Ding@glasgow.ac.uk
}

*corresponding author 


\section{INTRODUCTION}

In principle all firms in China are subject to political control - i.e., there is a lishu relationship, which means firms are “subordinate to” political influence. In practice the lishu relationship includes “... approvals for licences, domain, major projects, major operations decisions (such as profit distribution and investment) and firm structures” (Tan et. al., 2007, p. 788), all of which are set to meet political objectives. As well as controls, the lishu relationship also involves government support and subsidies (e.g., access to finance, more favourable tax treatment, granting of contracts, access to raw materials and other 'scarce resources ${ }^{1}$, etc.). The relationship is much stronger for publicly owned firms (e.g., state-owned enterprises, or SOEs, and collectively owned enterprises), who are also expected to meet certain 'social' goals set by politicians, such as employment targets, but it can still be relevant to privately-owned and foreign-owned firms (either because of the strength of political connections and/or because of intervention by government). ${ }^{2}$ However, Xia et. al. (2009) state that over time the importance of lishu has diminished especially following reforms introduced in 1997, and the vast majority of newly established privately owned firms that have set up in China since the late 1990s have opted not to have any (formal) lishu relationship with the government (central, regional or local).

According to Wu et. al. (2012), the evidence on the impact of political connections on firm performance across a number of (mostly developing) countries is mixed. Previous work

\footnotetext{
${ }^{1}$ Closer ties to government can also help businesses to overcome market and state failures in securing property rights and enforcing contracts - Li et. al., (2008) and Zhou (2013). Note, therefore, this definition of politically connected firms is different to the approach adopted by Faccio (2006), who looked at such connections across 47 countries (excluding China).

${ }^{2}$ An essential difference in the lishu relationship between publicly-controlled and privately-owned firms tends to be that the former are more beset with meeting policy goals (e.g., employment) rather than receiving favourable treatment such as subsidies and/or access to finance (Wu et. al., 2012).
} 
based on Chinese data tends to support the expectation that stronger lishu relationships and/or being publicly-owned (especially an SOE) may increase firm value and profitability, but have higher associated agency costs leading to lower productivity (i.e., efficiency and innovativeness). Thus, Sun et. al. (2002) show an inverted U-shaped pattern between government ownership and firm profitability, while Xia et. al. (2009) found that publicly-controlled Chinese firms privatised or incorporated in 2001 went on to experience gains in productivity. Li et. al. (2008) show that political connections increased firm profitability; while Chan et. al. (2012) and Chow et. al. (2012) show that a firm with politically connected CEO/Chairman faced lower financial constraints; and Wu et. al. (2012) and Guo et. al. (2014) found that politically connected managers in private firms secured more government subsidies. In addition, using the same dataset as in this work, Berkowitz et al. (2014) found that SOEs remained highly profitable due to their preferential access to cheap capital and the declining pressure to hire excess labour during 1998-2007; however, such changes did not generate improvements in total factor productivity TFP in the state-owned sector. Chen et. al. (2011) also found that being an SOE and/or having high political connectedness distorted investment behavior and harmed investment efficiency. Liu and $\mathrm{Li}$ (2015) find that the SOEs are less likely, compared to private firms, to exit the market because of low productivity. SOEs may be less efficient but have better access to external finance, whereas more efficient private firms are financially constrained; thus, preferential access to finance weakens the market selection mechanism and may lead to the lower, on average, productivity.

Most of the studies cited for China present empirical results not grounded in a theoretical model and, to this extent, are limited in scope. Thus in the next section we contribute to the literature by providing theoretical underpinnings as to when and how firms with stronger political affiliation and/or with higher share of the government-owned capital 
will have lower TFP in comparison to the firms with weaker political affiliation and lower share of state capital. We also show that this inverse relationship strengthens with liberalisation, or an increase in the openness of the Chinese economy, which has been a feature given reforms in the 1990’s and China's accession to the WTO in 2001.

Having set out a model that provides insights into the relationship between lishu, state ownership and productivity, in Section 3 we investigate the empirical relationship between the share of state ownership, the degree of political connections, and the firm productivity using firm-level data from China between 1998 and 2007. We find generally that the firms with the highest levels of TFP had low levels of political affiliation and/or state ownership; indeed most of the contribution to TFP growth came from new entrants, with no lishu links to the government. At the same time, predominantly state owned firms, operating in markets with high levels of firm entry (where liberalisation was important) also contributed significantly to the TFP growth. While (some of) these results can be explained by predictions made by the extant literature on political connections in China (see above), we believe this paper is the first to set out a detailed theoretical model and provide a direct empirical link (for different industries) between TFP and political connections/state ownership, building on our previous work as set out in Ding et. al. (2016).

\section{THEORETICAL MODEL}

In this section we develop a version of Schumpeterian model of growth with heterogeneous firms and the threat of entry to analyse the effect of the institutional environment on productivity. In order to address our empirical findings, reported in the next section, we model explicitly the interaction between the investment decision of a firm, its degree of its political affiliation, and the extent of state-ownership. Such a situation is more relevant for the Chinese economy, where state ownership of capital and government control over business 
management have remained relatively strong during the transition, but can also apply to economic and political environment in other developing and developed countries.

The framework is similar to Aghion et al. (2005) who analyse how firms react to liberalisation of an economy leading to an increase in the entry threat. The incumbent firms can improve their chance to remain in the market by undertaking a costly investment in innovation. Aghion et al. (2005) assume that the probability of successful innovation is determined by the level of investment, and that the firms choose the amount of investment so as to maximize their expected profits, as it is standard in the literature. In our model the decision is made by a manager, and the probability of successful innovation depends both on the level of investment and on the managerial time or efforts devoted to the firm's operation. However, the managers may pursue private objectives and can divert their time and effort from productive activities to seeking private rewards, for example, by establishing political connections. The extent to which the owners can control the manager depends on the ownership structure: private ownership implies stronger market discipline, whereas state ownership is more likely to lead to weaker monitoring and larger managerial slack (Ehrlich et al., 1994). The trade-off between profits and private reward depends on the institutional environment: state ownership leads to a larger departure from profit maximization but may offer a privileged position in the market, such as access to scarce or cheaper inputs or preferential taxes, and, thus, overall higher net profit. These links result in a rich picture of possible outcomes and helps us to explain the patterns in productivity observed in the data regarding the effect of the interaction between liberalization and ownership structure. 


\section{Production and investment}

Consider an economy with a continuum of firms, each producing one intermediate good that are combined in production of the final good (numeraire) according to the production function

$$
y_{t}=\frac{1}{\alpha} \int_{0}^{1}\left[A_{t}(v)\right]^{1-\alpha}\left[x_{t}(v)\right]^{\alpha} d v, \quad \alpha \in(0,1)
$$

Here $x_{t}(v)$ is the quantity of intermediate input of type $v$, and $A_{t \cdot}(v)$ is the quality or productivity of $v$ used in period $t$. The final good can be used for consumption, for the production of intermediate goods, and for investment in innovation. It is assumed that the final good is produced competitively, and so each input is paid its marginal product. Solving the optimisation problem for the choice of inputs gives the inverse demand for type $-v$ input as $p_{t}(v)=\left[\frac{A_{t}(v)}{x_{t}(v)}\right]^{1-a}$. Each firm has access to technology for converting one unit of final good into $\varphi$ units of output. Thus, $\pi_{t}(v)=\left[p_{t}(v)-\frac{1}{\varphi}\right] x_{t}(v)$, where $\frac{1}{\mathscr{c}}$ is the production cost. Profit maximisation gives the optimal output, $\tilde{x}_{+}(v)=\lceil\alpha \varphi\rceil^{1 /(1-\alpha)} A_{t}(v)$, the equilibrium price, $\quad \tilde{p}_{t}(v)=1 / \alpha \varphi$, and the resulting profit level (surplus), $\tilde{\pi}_{+}(v)=(1-\alpha)\lceil\alpha \varphi\rceil^{\alpha /(1-\alpha)} A_{+}(v)$. The aggregate output of the final good is then given by $y_{t}=\alpha^{(2 \alpha-1) /(1-\alpha)} \varphi^{\alpha /(1-\alpha)} A_{t}$, where $A_{t}=\int_{0}^{1} A_{t}(v) d v$ is the average productivity in the economy.

The technology is characterised by the productivity frontier, $\bar{A}_{t}$, growing at an exogenous rate $g$, where $\bar{A}_{t}=\bar{A}_{t-1}(1+g)$. At the end of period $t-1$ each firm can be in one of two states, the high-productivity state with $A_{t-1}(v)=\bar{A}_{t-1}$ (at the frontier) or the low-productivity state with $A_{t-1}(v)=\bar{A}_{t-2}$ (one step behind the frontier). Before choosing the production plan a firm can invest in an intangible asset (e.g., R\&D) intended to improve productivity, with a stochastic outcome. If successful, the firm's productivity increases by a factor of $(1+q)$, that is, moves one step up the quality ladder; if unsuccessful, productivity 
remains the same. As in Aghion et al. (2005), we assume that successful firms which were high-type at $t$-1 start as high-type at $t$, and all other firms start as low-type (unsuccessful low-type firms leapfrog to the next step due to some spill-overs). The cost of the intangible investment is increasing and convex in the probability of success, $z$, and increasing and linear in the current state of technology, $C\left(z, A_{t-1}(v)\right)=\frac{c}{2} z^{2} A_{t-1}(v)$.

There is a pool of potential entrepreneurs who can enter the market to produce the intermediate good $v$ and replace an incumbent firm with an exogenous probability $h$. The new entrant will find the entry profitable if it can produce at the technology frontier. Thus, for incumbent firms at the frontier $h=0$, and for the incumbent firms below the frontier $h>0$. Higher $h$ means lower barriers to entry, and an increase in $h$ can be interpreted as liberalisation of the economy.

Assume an intermediate firm is allowed to keep fraction $\beta$ of the surplus it produces, so that its net profit in period $t$ is

$$
\pi_{+}(v)=\beta(1-\alpha)\lceil\alpha \varphi\rceil^{\alpha /(1-\alpha)} A_{t}(v)=\delta A_{t}(v)
$$

where $\delta=\beta(1-\alpha)\lceil\alpha \varphi\rceil^{\alpha /(1-\alpha)}$ is the profitability parameter. At the end of period $t$-1 firms choose to invest in intangible assets in order to maximise their expected profit net of investment cost. For an advanced, or a high-type firm (on the productivity frontier), the expected profit net of investment is:

$$
\pi^{H}=\delta\left[z \bar{A}_{t}+(1-z)(1-h) \bar{A}_{t-1}\right]-\frac{c}{2} z^{2} \bar{A}_{t-1}(4 \mathrm{a})
$$

and for a low-type firm:

$$
\pi^{L}=\delta\left[z(1-h) \bar{A}_{t-1}+(1-z)(1-h) \bar{A}_{t-2}\right]-\frac{c}{2} z^{2} \bar{A}_{t-2}
$$

\section{$\underline{\text { Political connections and TFP growth }}$}

We now investigate how political affiliation and share of government-owned capital can affect the equilibrium through the manager's decision on time allocation. In our model we 
treat state control and political connections separately: specifically, the degree of state control is assumed to be exogenous and taken as given by the firm, whereas the extent of political connections can be chosen strategically by the firm's manager. Our approach can be easily extended to include the degree of state control as the choice variable, with qualitatively similar results (available upon request).

We assume that the firms are characterized by an exogenously determined degree of state control, which here depends on the share of state-owned capital, $s \in[0,1$, and that the firm managers, in addition to pursuing profit maximization objective, can also pursue their selfish objectives, for example, by building up political capital and maintaining political connections. ${ }^{3}$ This assumption is formulated similarly to Ehrlich et al. (1994): the objective function of a manager takes the form

$$
V(s, m)=\lceil 1-\sigma(s)\rceil \pi+\sigma(s) r(m)
$$

where $r(m)$ is the private reward function, $\sigma(s)$ is the relative weight assigned to private reward, and $m$ is the fraction of manager's time devoted to pursuing private reward by developing political connections. As in Ehrlich et al. (1994) we assume $\sigma^{\prime} \geq \mathcal{C}$, $r(0)=0, r^{\prime}>0$, and $r^{\prime \prime} \leq 0$. That is, the weight on profits is lower in state-owned firms because of the imperfect control by owners, political or regulatory constraints, weaker monitoring and a weaker market-driven discipline. It is also assumed that $\sigma(0) \geq \mathcal{C}$ (this holds with equality if in private firms managers are only concerned with profit maximization and do not seek private rewards) and $\sigma(1)<1$ (this condition ensures strictly positive

\footnotetext{
3 Alternatively, one can assume that SOE managers have an objective of employment protection; this can be modelled in a standard neoclassical framework, as in Ehrlich et al. (1994). Other objectives, imposed by state control, could also be modelled explicitly, in a modified framework. Our approach represents deviation from profit-maximising behaviour, imposed and rewarded by the state, in a general "reduced" form.
} 
weight on profits in state-owned firms). ${ }^{4}$ The remaining fraction of a manager's time, $(1-m)$, is devoted to entrepreneurial activities, in particular investing in $R \& D$, with the probability of the success of an innovation being an increasing function of the time devoted to this activity. For simplicity we assume that the probability of success is a linear function of managerial time, $z=\hat{z}(1-m)$, where $\hat{z} \in(0,1)$ is the exogenous success rate when $m=0$. A firm's manager maximizes their objective function by choosing time allocation, before making the production decision.

As a benchmark, consider, first, the objective of a manager of a private firm when the weight on the private reward is zero:

$$
V^{H, L}(s, m)=\pi^{H, L}(\hat{z}(1-m))
$$

Since $\frac{\partial \pi^{H, L}}{\partial m}<0$, the optimal choice is $m^{H, L}=0$, and so $z^{H, L}=\hat{z}^{H, L} \cdot{ }^{5}$

Now we investigate how political affiliation and share of government-owned capital can affect the equilibrium. With $\sigma(s)>0$ the objective function becomes

$$
V^{H}=(1-\sigma)\left(\delta\left[z \bar{A}_{t}+(1-z)(1-h) \bar{A}_{t-1}\right]-\frac{c}{2} z^{2} \bar{A}_{t-1}\right)+\sigma r(m)
$$

$$
V^{L}=(1-\sigma)\left(\delta\left[z(1-h) \bar{A}_{t-1}+(1-z)(1-h) \bar{A}_{t-2}\right]-\frac{c}{2} z^{2} \bar{A}_{t-2}\right)+\sigma r(m)
$$

where $z=\hat{z}(1-m)$.

\footnotetext{
${ }^{4}$ Groves et al. (1995) find that in Chinese state-owned firms managerial pay was positively correlated to profits and sales, and with reform the correlation with profits strengthened whereas the correlation with sales weakened. At the same time, the overwhelming majority of managers were appointed by the old-system industrial bureaus which, plausibly, gave room to the importance of creating and maintaining political connections for the managers, and limited the scope for market forces.

${ }^{5}$ If managers of private firms do not deviate from profit maximization then they optimally choose not to invest time in building political connections. This would also imply that private firms either have no political affiliation, or that their political affiliation does not build up.
} 
We are interested in an interior solution. This is described by the following first-order conditions:

$$
\frac{d V^{H}}{d m}=(1-\sigma)\left(-\delta(g+h) \hat{z}+c \hat{Z}^{2}(1-m)\right) \bar{A}_{t-1}+\sigma r^{\prime}(m)=\mathcal{C}
$$

$$
\frac{d V^{L}}{d m}=(1-\sigma)\left(-\delta g(1-h) \hat{Z}+c \hat{Z}^{2}(1-m)\right) \bar{A}_{t-2}+\sigma r^{\prime}(m)=\mathrm{C}
$$

which can be rewritten as:

$$
\begin{aligned}
& \sigma r^{\prime}\left(m^{H}\right)=(1-\sigma) \hat{z} \bar{A}_{t-2}(1+g)\left\lceil\delta(g+h)-c \hat{z}\left(1-m^{H}\right)\right] \\
& \sigma r^{\prime}\left(m^{L}\right)=(1-\sigma) \hat{z} \bar{A}_{t-2}\left[\delta g(1-h)-c \hat{z}\left(1-m^{L}\right)\right\rceil
\end{aligned}
$$

In the optimum a manager equates the marginal loss in profits (the right-hand-side of (9)) to the marginal increase in private reward (the left-hand-side of (9)). By weak concavity of the private reward function, the left-hand side of (9) is a non-increasing function of $m$. The marginal loss in profits in the right-hand side of (9) is linearly increasing in $m$, and for any given $m$ it is greater by the factor of $(1+q)$, for a high-type firm than for a low-type firm. Therefore, in equilibrium $m^{L}>m^{H}$ : a manager of a low-type firm devotes more time to building political capital and raising private reward and, consequently, less time to $R \& D$ activities, in comparison to a manager of a high-type firm; as a result, the probability of TFP growth is lower for low-type firms.

\section{Liberalization and TFP growth}

Consider a liberalization reform leading to the lower barriers to entry (higher $h$ ). Differentiating the first-order conditions (equation 9) with respect to $h$ and rearranging the terms we obtain:

$$
\frac{d m^{H}}{d h}=\frac{\delta \hat{z}}{\left[\frac{\sigma}{1-\sigma} r^{\prime \prime}\left(m^{H}\right)-c \hat{Z}^{2} \bar{A}_{t-1}\right]}<0
$$




$$
\frac{d m^{L}}{d h}=\frac{-\delta g \hat{z}}{\left[\frac{\sigma}{1-\sigma} r^{\prime \prime}\left(m^{L}\right)-c \hat{z}^{2} \bar{A}_{t-2}\right]}>0
$$

Thus, higher liberalization reduces the time devoted to private reward (and thus leads to lower political connections) for a more productive firm, and increases it for a low-type firm; this has a positive effect on the probability of TFP growth for the high-type firms and a negative effect for the low-type firms. This result is similar to the one obtained in Aghion et al. (2005): liberalization incentivizes innovation for the advanced firms but has an opposite effect for the less advanced firms.

\section{Ownership structure and TFP growth}

We now investigate the effect of the share of state ownership, $s$, on TFP growth. Observe that for both types of firms where managers pursue selfish objectives $(\sigma>0)$ the probability of TFP growth is lower than that for firms where managers do not deviate from profit maximization (s=0), since $\hat{z}\left(1-m^{H, L}(s)\right)<\dot{z}$, as long as $m^{H, L}(s)>0$. If state ownership affects only the relative weights on profits and private rewards in the objective function $(\sigma=\sigma(s)$ with $\frac{d \sigma}{d s}>0$ ), then a higher share of state ownership unambiguously leads to the lower probability of TFP growth. This is established by differentiation of (9) with respect to the relative weight assigned to private reward, $\sigma$ :

$$
\begin{aligned}
& \frac{d m^{H}}{d \sigma}=-\frac{1}{(1-\sigma)^{2}} \frac{r^{\prime}\left(m^{H}\right)}{\left[\frac{\sigma}{1-\sigma} r^{\prime \prime}\left(m^{H}\right)-c \hat{z}^{2} \bar{A}_{t-1} \mid\right.}>0 \\
& \frac{d m^{L}}{d \sigma}=-\frac{1}{(1-\sigma)^{2}} \frac{r^{\prime}\left(m^{L}\right)}{\left|\frac{\sigma}{1-\sigma} r^{\prime \prime}\left(m^{L}\right)-c \hat{Z}^{2} \bar{A}_{t-2}\right|}>0
\end{aligned}
$$

These inequalities show that for both types of firms, the more the manager deviates from the profit-maximizing objective (i.e., the higher weight they put on private reward), the 
less time they devote to R\&D activities (and/or other technology enhancing activities), and the lower is the probability of TFP growth. Furthermore, since $\frac{d \sigma}{d s}>C$, from (11) it follows that $\frac{d m^{H, L}}{d s}=\frac{d m^{H, L}}{d \sigma} \frac{d \sigma}{d s}>0$; in firms of both types with a higher degree of state ownership, managers devote more time to pursuing their private objectives and less time to productive activities, resulting in a lower probability of TFP growth. This unambiguous outcome is based on the assumption that state ownership only affects the objective of the manager.

\section{Ownership structure, market privileges, and TFP growth}

It is possible, however, that the degree of state control has a direct effect on the market position of a firm. For example, there is evidence in the literature (cited in the introduction) that in China firms with higher political affiliation and/or higher share of government-owned capital enjoy various perks, such as more favourable tax treatment, better access to financing or to scarce resources, such as land, etc. With reference to equation (4), this means that firms with a higher share of state capital retain a higher share of profit, $\beta$, (e.g., through a lower tax rate) and/or they face lower production cost, $1 / \varphi$ (e.g., through input subsidies, access to cheaper or scarce inputs such as credit, land, and other resources). In this case for the profitability parameter, $\delta$, we have $\frac{d \delta}{d s}=\delta\left[\frac{1}{\beta} \frac{d \beta}{d s}+\frac{\alpha}{1-\alpha} \frac{1}{\varphi} \frac{d \varphi}{d s}\right]>0$ Differentiating (9) with respect to $\delta$ gives:

$$
\begin{aligned}
& \frac{d m^{H}}{d \delta}=\frac{-(g+h) \hat{z} \bar{A}_{t-1}}{-\left[\frac{\sigma}{1-\sigma} r^{\prime \prime}\left(m^{H}\right)-c \hat{z}^{2} \bar{A}_{t-1}\right]}<0 \\
& \frac{d m^{L}}{d \delta}=\frac{-g(1-h) \hat{z} \bar{A}_{t-2}}{-\left[\frac{\sigma}{1-\sigma} r^{\prime \prime}\left(m^{L}\right)-c \hat{z}^{2} \bar{A}_{t-2}\right]}<0
\end{aligned}
$$

Combining this with (11) gives the total effect of the share of government-owned capital on the manager's time allocation: 


$$
\begin{aligned}
& \frac{d m^{H}}{d s}=\frac{\frac{r^{\prime}\left(m^{H}\right)}{(1-\sigma)^{2}} \frac{d \sigma}{d s}-\frac{d \delta}{d s}(g+h) z \bar{A}_{t-1}}{-\left[\frac{\sigma}{1-\sigma} r^{\prime \prime}\left(m^{H}\right)-c \hat{z}^{2} \bar{A}_{t-1}\right]} \\
& \frac{d m^{L}}{d s}=\frac{\frac{r^{\prime}\left(m^{L}\right)}{(1-\sigma)^{2}} \frac{d \sigma}{d s}-\frac{d \delta}{d s} g(1-h) \hat{z} \bar{A}_{t-2}}{-\left[\frac{\sigma}{1-\sigma} r^{\prime \prime}\left(m^{L}\right)-c \hat{z}^{2} \bar{A}_{t-2}\right]}
\end{aligned}
$$

The total effect of state ownership on time allocation (and, therefore, on TFP growth) is now ambiguous and, in general, can be non-monotone. We analyze four possible cases next. ${ }^{6}$

Noting that $r^{\prime}\left(m^{H}\right)>r^{\prime}\left(m^{L}\right.$, and $(1+g)(q+h)>g(1-h)$ for all $h \in(0,1)$, it is easy to see from (10) that

$$
\begin{aligned}
& \frac{d m^{H, L}}{d s}>0 \text { iff } \frac{d \delta}{d s}<\frac{\min \left\{\frac{r^{\prime}\left(m^{H}\right)}{(g+h)(1+g)}, \frac{r^{\prime}\left(m^{L}\right)}{g(1-h)}\right\}}{(1-\sigma)^{2} \hat{z} \bar{A}_{t-\text { - }}} \frac{d \sigma}{d s} \\
& \frac{d m^{H, L}}{d s}<0 \text { iff } \frac{d \delta}{d s}>\frac{\max \left\{\frac{r^{\prime}\left(m^{H}\right)}{(g+h)(1+g)}, \frac{r^{\prime}\left(m^{L}\right)}{g(1-h)}\right\}}{(1-\sigma)^{2} \hat{z} \bar{A}_{t-?}} \frac{d \sigma}{d s}
\end{aligned}
$$

Two intermediate cases are also possible:

$$
\begin{aligned}
& \frac{d m^{H}}{d s}>0 \text { and } \frac{d m^{L}}{d s}<0 \quad \text { iff } \frac{r^{\prime}\left(m^{L}\right)}{(1-\sigma)^{2} \hat{z} \bar{A}_{t-2} g(1-h)} \frac{d \sigma}{d s}<\frac{d \delta}{d s}<\frac{r^{\prime}\left(m^{H}\right)}{(1-\sigma)^{2} \bar{z} \bar{A}_{t-2}(g+h)(1+g)} \frac{d \delta}{d s} \\
& \frac{d m^{H}}{d s}<0 \text { and } \frac{d m^{L}}{d s}>0 \quad \text { iff } \frac{r^{\prime}\left(m^{H}\right)}{(1-\sigma)^{2} Z \bar{A}_{t-2}\{(g+h)(1+g)} \frac{d \sigma}{d s}<\frac{d \delta}{d s}<\frac{r^{\prime}\left(m^{L}\right)}{(1-\sigma)^{2} \bar{z} \bar{A}_{t-2} g(1-h)} \frac{d \delta}{d s}
\end{aligned}
$$

Which of these four cases takes place depends on the configuration of parameters and on the curvature of the private reward function $r(m)$, the weight function, $\sigma(s)$, and the profitability function, $\delta(s)$. In particular, we are interested in the role of liberalization of the

\footnotetext{
${ }^{6}$ The four cases described in 13(a-d) correspond to the monotone effect of state ownership on TFP growth, which can be positive or negative and can also depend on the firm type. Non-monotone effects can be analyzed in the same way.
} 
economy, given its importance to China in this period (recall that in this model liberalization is interpreted as lowering barriers to entry, or $h$ approaching 1 ).

Case 1: Weak Privileges. Condition (13a) shows that, if the effect of state ownership on the profitability of the firms is weak ( $\frac{d \delta}{d \mathrm{~s}}$ is small) then an increase in the share of state-owned capital raises time spent on seeking private rewards (and, therefore, lowers the probability of TFP growth) for both types of firms. This is more likely to be the case when the weight assigned to the private reward is high ( $\sigma$ is close to 1 ) and the exogenous rate of growth is low ( $g$ is close to zero). Intuitively, when state ownership does not give much commercial benefits, such as tax or credit perks, especially when this is coupled with overall low growth opportunities, the effect of private reward dominates.

Case 2: Strong Privileges. On the other hand, condition (13b) implies that for a sufficiently strong positive effect of state ownership on the profitability of firms ( $\frac{d \delta}{d s}$ is large) the time spent on seeking private rewards is lower (the probability of TFP growth is higher) for both types, the higher is the share of state ownership. This is more likely to be the case when the weight assigned to the private reward is low and the exogenous rate of growth is high. This is the opposite of the previous case: when the commercial benefits from state ownership are high, especially when coupled with overall high growth opportunities, the profit effect dominates, causing managers to spend more time on R\&D activities.

Case 3: Weak Reward. Now consider the first intermediate case, (13c). The necessary condition for this inequality to hold is $\frac{r^{\prime}\left(m^{L}\right)}{r^{\prime}\left(m^{H}\right)}<\frac{g(1-h)}{(g+h)(1+g)}$ If $r(m)$ is a strictly concave function, and in equilibrium $m^{L}>m^{H}$, this condition means that the rate of increase in the private reward function is sufficiently low; hence, we label this case "weak reward”. In this situation in more advanced firms higher state ownership increases the probability of TFP 
growth, whereas the converse is true for less advanced firms. When private reward function is linear the necessary condition is violated, and so (13c) cannot hold.

Case 4: Strong Reward. Finally, (13d) describes the situation where higher state ownership lowers the probability of TFP growth for the high-type firms and raises it for the low-type firms. Equivalently, with lower state ownership the probability of TFP growth increases for more advanced firms and falls for less advanced firms. The necessary condition for this inequality to hold is $\frac{r^{\prime}\left(m^{L}\right)}{r^{\prime}\left(m^{H}\right)}>\frac{g(1-h)}{(g+h)(1+g)}$. This means, conversely to the previous case, that for a strictly concave private reward function the rate of increase in private reward is sufficiently high. As $h$ approaches 1 , the right-hand side of this inequality tends to zero, and thus the inequality is more likely to hold. Therefore, the model predicts that this situation is more likely with higher liberalization: firms with higher productivity will tend to be the ones with lower state ownership. Firms with lower productivity have a higher chance to survive in the market if they have higher state ownership; nevertheless, these firms will be eventually replaced by more productive firms. Note that the necessary condition always holds for the linear reward function.

To summarize, (13) describes the effect of state ownership on the probability of TFP growth, through the optimal choice of time allocation of a firm's manager between profit-maximizing activities (in particular, growth-enhancing R\&D) and activities increasing private reward (such as building political connections). The relationship between state ownership and TFP growth is inverse for both high-type and low-type firms when state ownership has a weak effect on firms' profitability. It is possible, when state ownership has strong positive effect on profitability, that it also has a positive effect on the probability of TFP growth, but only for the low-type firms; for the high-type firms the relationship is still negative. In both cases the relationship is strengthened with higher liberalization of the economy. 
The model predictions, to a certain extent, echo recent empirical observations on the distribution of productivity (Yu et al. 2015) and growth (Duschl and Peng, 2015) among Chinese firms, by type of ownership. Thus, Yu et al. (2015) find heterogeneous dynamics in labour productivity across ownership types as well as within each type. In particular, they demonstrate that while overall SOEs are catching up in labour productivity, there is a group constantly lagging behind. Their work also shows evidence of eventual "weeding-out” of low-productivity firm within each type of ownership. Duschl and Peng (2015) find similar heterogeneity in their study of the distribution of firms' growth (measured, alternatively, by the number of employees and by sales) by ownership type. Heterogeneity appears to be highest among SOEs: they are more likely, in comparison to other types, to have higher growth rates, primarily because of their privileged access to resources. However, the worst-performing SOEs are more likely to survive and coexist with more efficient firms.

\section{THE EFFECT OF STATE OWNERSHIP AND LISHU ON PRODUCTIVITY}

In this section we present some empirical findings on the relationship between the share of state ownership, the extent of political affiliation, and TFP for Chinese firms during 1998-2007. In particular, we consider whether there is any empirical support for the main predictions from our theoretical model: that higher political connections are linked to lower TFP (growth); liberalization lowers the incentive for a lishu relationship (especially in more productive firms); but the relationship between ownership, TFP and political affiliation is more complicated and depends on whether the (private) reward to having strong political connections results in higher profits.

We have previously provided estimates of TFP, and thus identified which firms are at the technological frontier, in Ding et. al. (2016). We used a system Generalised Methods of Moments (GMM) approach to estimate log-linear Cobb-Douglas gross-output production functions for 26 industries in China, using annual firm-level National Bureau of Statistics 
(NBS) data for $1998-2007,{ }^{7}$ to compute measures of TFP as the level of output that is not attributable to factor inputs (i.e., productivity is due to efficiency levels and technical progress):

$$
\ln \widehat{T F} P_{i t}=y_{i t^{-}} \frac{1}{\hat{\alpha}_{F}+\widehat{Q}_{F}+\hat{\alpha}_{K}}\left(\hat{\alpha}_{E} e_{i t}-\hat{\alpha}_{F} f_{i t}-\hat{\alpha}_{K} k_{i t}\right)
$$

where endogenous $y, e, f$ and $k$ refer respectively to the logarithms of real gross output, employment, intermediate inputs, and the capital stock in firm $i$ at time $t$ $(i=1, \ldots, N ; t=1, \ldots T)$.

Of particular importance for our research question is the index of firms' political affiliation (or lishu relationship) with the central, provincial, and local governments (Li, 2004; Tan et al., 2007; Xia et al., 2009). This lishu relationship was explained and discussed in the introduction. Here we classify firms into three groups according to various degrees of political affiliation, i.e. high political affiliation (firms affiliated with central or provincial governments), medium political affiliation (firms affiliated with local governments such as city-, district-, county-, prefecture-, township- and village-level governments), and no political affiliation (those having no affiliation with government at any level). ${ }^{8}$ Table 1 in the Appendix shows that the political affiliation of firms changed significantly over the period (e.g., 16\% of firms had no affiliations in 1998, but by 2007 this had risen to 76\%); in

\footnotetext{
${ }^{7}$ A discussion of the unbalanced panel dataset used - the annual accounting reports filed by industrial firms with the NBS over the period of 1998-2007 - is presented in Ding et. al. (2016). This dataset includes all SOEs and other types of enterprises with annual sales of five million yuan (about $\$ 817,000$ ) or more. Brandt et al. (2012.) provide a thorough discussion of this dataset, which for present purposes covered nearly 600 thousand firms, which corresponds to some 2.2 million firm-year observations.

${ }^{8}$ Note, the information on lishu we use from the NBS database refers to a self-reported variable setting out if the firm had political connections and with which level of government (the variable name is 隶属关系).
} 
addition, there was a large decline in the importance of SOE's and a rise in firms privately-owned by individuals (e.g., 32\% firms were state-owned in 1998, falling to 4\% by 2007). This period coincided with rapid liberalization of the Chinese economy, coinciding with the 'open door' reforms starting in 1992 and China's accession to the WTO in December 2001; for example, Du et. al. (2014) show that between 1998 and 2007 average tariffs fell for final goods and input tariffs by $87 \%$ and 36\%, respectively (Table 1 shows the average fall in tariffs for the firms used in this study).

Regarding the distribution of TFP across firms, Figure 1 shows this for the three sub-groups with different levels of political affiliation; the TFP distribution for the firms with no political affiliation dominates the distribution for those with high political affiliation: the empirical cumulative distribution function (cdf) of the former is everywhere below, or to the right from the empirical cdf of the latter (the Kolmogorov-Smirnov, or KS test shows that the maximum gap between the distribution for firms with no affiliation and firms with some affiliation has a value of $0.18^{9}$ and is significant at the $1 \%$ level). This is in line with the overall prediction of the model presented in Section 2.2 - the more managers deviate from profit-maximisation (by pursuing private rewards through political affiliation), the less time they devote to technology enhancing activities, and the lower is TFP (and its growth). Figure 2 compares the distribution of firms with more than $25 \%$ of state ownership and those with less than $25 \%$ of state ownership. We observe that the TFP distribution of those with lower state ownership dominates that of firms with higher state ownership with a highly significant KS value of 0.33 .

\footnotetext{
9 This represents the largest proportional gap between the two distributions.
} 
FIGURE 1

TFP distribution: political affiliation comparison

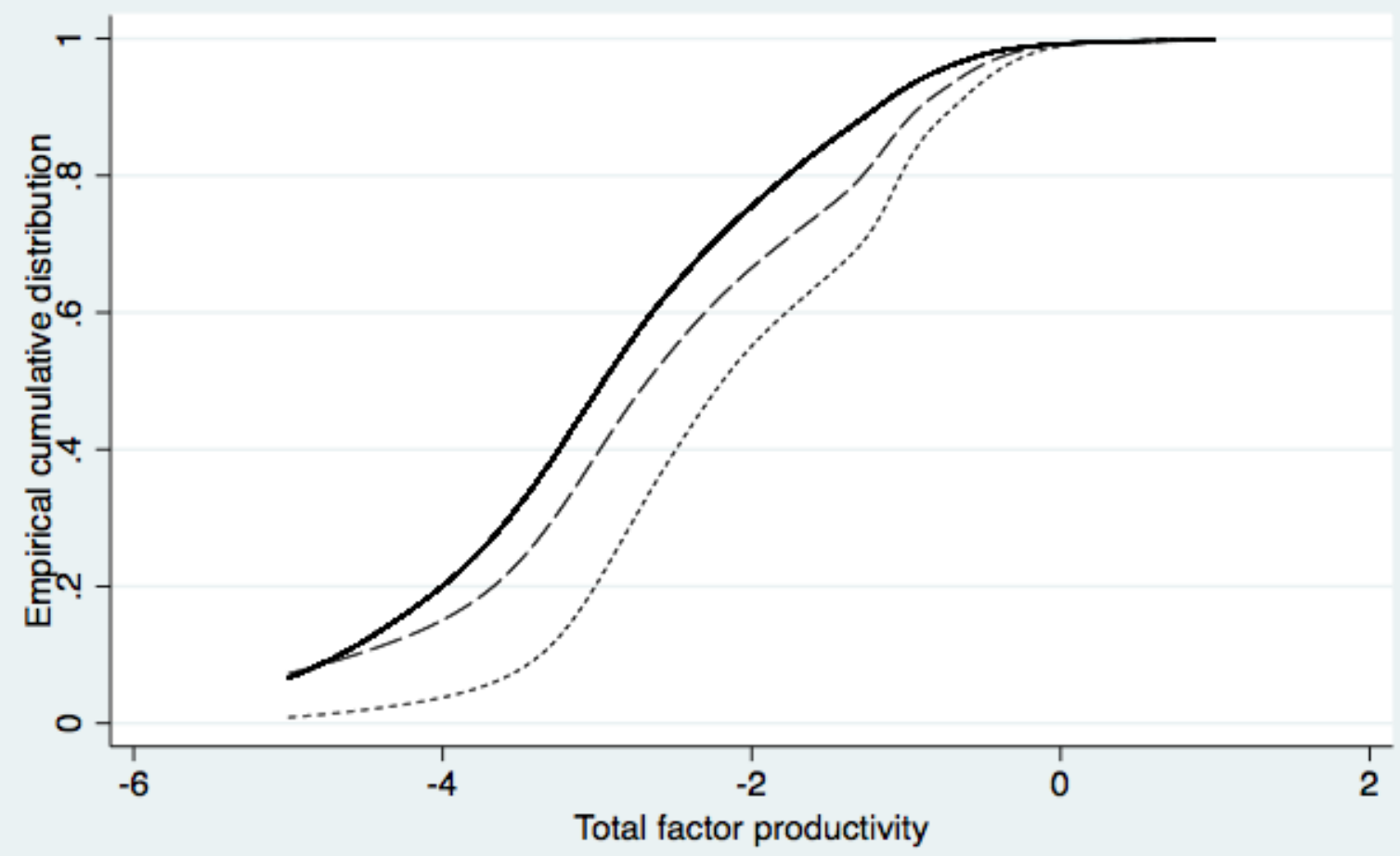

links with Central/Provincal govt. $\quad---$ medium political affiliation no such links

FIGURE 2

TFP distribution: ownership comparison




approach taken by Haltiwanger (see Foster et. al., 1998) ${ }^{10}$ is applied to decompose measures of productivity growth into various components that represent the impact of resource allocation across surviving firms, as well as the impact on productivity of the entry and exit of firms. Both aggregate results, and those for the relative contributions of various sub-groups (by political affiliation and by state-ownership) to overall TFP growth, are provided in Table 2 in the Appendix. The third row, labelled "all firms", shows that, based on the system GMM estimation, Ding et. al. (2016) found that annual growth in TFP between 1998 and 2007 in Chinese industries was overall 9.6\%. As can be seen, this very large TFP growth was almost completely attributable to new firms entering post-1998 with relatively higher TFP. This finding is consistent with (although stronger than) the conclusion by Brandt et al. (2012) that net entry accounts for over two thirds of total TFP growth. There was no increased productivity through the exit of firms with relatively lower TFP (indeed there is evidence that higher productivity firms were closed); and improvements due to firms becoming themselves more productive over time were relatively small. Reallocations of resources (through contraction and expansion of output shares in firms of different productivity levels) increased aggregate TFP growth by $2.4 \%$ p.a. - i.e. resources were reallocated to more efficient firms through this mechanism. ${ }^{11}$

The top panel of Table 2 shows the actual contribution of firms, grouped by political affiliation, to overall TFP growth; firms with no political affiliation account for nearly $62 \%$

\footnotetext{
10 The basic model is set out in the appendix. As will be seen, we combine the between-firm and cross-firm effects obtained from the Haltiwanger approach into one 'between firm' effect. While the separate information is of some interest, we are mainly concerned with whether there were changes in TFP within firms, between firms, or through entry and exit.

11 These results are overall consistent with Song et. al. (2011), where the theoretical model and the empirical analysis was focused on TFP growth through reallocation of resources.
} 
of overall growth (i.e., $5.9 \div 9.6$ ). In relative terms, given their initial share of output in 1998 , this difference is even more dramatic, and most of this contribution to TFP growth came from new firms entering by 2007 that had no lishu links with government. Firms with medium-level affiliation (the largest sub-group in 1998) experienced overall negative TFP growth, caused by the closure of productive firms. For those with high-level provincial and central government links, growth in TFP was significant (although less dramatic when compared to those with no affiliation - given their output share in 1998) and this was mainly attributable to the reallocation of market shares to more productivity firms (accounting for $49 \%$ of TFP growth for this sub-group), followed by firms in operation throughout 1998-2007 that internally improved their productivity (34\% of the total), and by the closure of low productivity firms (this accounts for nearly $27 \%$ of sub-group TFP growth). New established firms were marginally less productive than existing firms.

When firms are grouped into three levels of state ownership of share capital, ${ }^{12}$ the results in Table 2 show that in firms with over 50\% ownership contributed nearly $26 \%$ to aggregate TFP growth. In relative terms, given their share of output in 1998, they experienced a lower per annum TFP growth rate than firms with less than $25 \%$ state ownership. Columns (4) and (5) show that TFP growth for firms with low state ownership was driven by the entrance of new, more productive firms (counterbalanced to some extent by the closure of more productive firms with mainly medium-level political affiliation). For firms with the highest levels of state ownership, $45 \%$ of TFP growth is attributable to

\footnotetext{
12 Note, the (Spearman rank) correlation between the three levels of political affiliation and ownership sub-groups (the five sub-groups used in this study) is -0.34 ; the correlation between political affiliation and whether the firm is state-owned (using the three levels of state ownership of share capital shown in Table 2) is 0.45. Thus, there is a strong correlation between political affiliation and state-ownership, but note they are not equivalent.
} 
reallocation of market shares between firms, 32\% to the closure of firms with low TFP, and nearly $28 \%$ to within firm improvements in TFP during 1998-2007. Clearly during this period SOE's were undergoing restructuring to improve their productivity performance.

While firms with no political affiliation and low levels of state ownership outperformed other firms, Table 2 shows that there is evidence that firms with high levels of political links and high state control also performed relatively well. As we showed in Section 2.5 (cases 2 and 3), this can be explained by the dual effect that political links and state control may have on productivity when there is a strong positive effect of state ownership on profitability and/or there are strong rewards to higher levels of political affiliation with government. That is, strong political connections come at the cost of pursuing objectives other than profit maximisation (such as private rewards to managers, as in our model, or, for example, participation in government employment programmes, etc.) and subsequent efficiency loss; however, firms with high political affiliations and/or a high share of state ownership enjoy various tangible benefits, such as a more favourable tax treatment or a better access to bank credit or scarce resources, which may help them to maintain higher productivity levels. Depending on the degree of liberalization of the economy, higher state ownership and political connections could then be associated with higher TFP growth, which is something we explore in more detail next.

To gain further insights into the links between TFP, state ownership, liberalisation and political connections, a multinomial logit model is estimated that determines the level of affiliation of firm $i$ in time $t$. The variables used are set out in Table 1, comprising a comprehensive list of potential determinants including the size of the firm, its TFP level, age, ownership, location effects, whether a firm engaged in exporting and/or undertook R\&D, and variables representing different aspects of the liberalisation of the Chinese economy (cf. tariff rates and new firm entry). The model estimated was: 


$$
\begin{gathered}
P A_{i t .}=\gamma_{0}+\gamma_{1} P A_{i t-1}+\gamma_{2} \ln T F P_{i t}+\gamma_{3}(\ln T F P \times \text { Tariff })_{i t}+\gamma_{4}(\ln T F P \times \text { New firm rate })_{i t}+ \\
\quad \begin{aligned}
\gamma_{5}(\ln T F P & \times t)_{i t}+\gamma_{6}(\ln T F P \times S O E)_{i t}+\gamma_{7}(\ln T F P \times \text { foreign-owned })_{i t} \\
& +\gamma_{8}(\ln T F P \times H K / M a c a u / T a i w a n)_{i t}+\gamma_{9}(\ln T F P \times \text { collective-owned })_{i t} \\
& +\gamma_{x} X_{i t}+u_{i t}
\end{aligned}
\end{gathered}
$$

where $P A_{\mathrm{it}}$ represents the three levels of political affiliation in Table 1 ; $\ln$ TFP enters combined with a number of variables (e.g., liberalisation and ownership) that mediate between TFP and the type of political affiliation pursued by firms; and $X_{\mathrm{it}}$ represents all the other covariates in Table 1.

Table 4 in the Appendix reports the values of $\hat{\gamma}$ obtained when estimating equation (2), with 'medium affiliation' chosen as the baseline. The interaction terms involving $\ln$ TFP are generally highly significant, and overall the model achieves a good 'fit' in terms of predicting which level of affiliation firms chose (cf. the high pseudo- $\mathrm{R}^{2}$ obtained). Marginal effects $\left(\frac{\partial \hat{p}(P A}{\partial x}\right)$ are reported in Table 3, taking account of the interaction effects, and these show that (cet. par.) the past affiliation sub-group of a firm is a strong indicator of current affiliation (i.e., there is significant inertia due to large 'fixed' and 'sunk' costs with few firms changing their affiliation status in the short- to medium-term ${ }^{13}$ ). For example, firms in the high affiliation sub-group in $t-1$ where over $81 \%$ more likely to be in this sub-group in period $t$; those having medium affiliation in in $t-1$ where over $65 \%$ more likely to belong to the same sub-group in $t$; and those belonging to the medium (high) affiliation sub-groups in $t$ -1 where $-65 \%$ (-72\%) less likely to have no political affiliation in $t^{14}$

\footnotetext{
13 Across 1998-2007, just under $9 \%$ of firms that existed in at least two consecutive years changed their political status (based on the three sub-groups used here). The growth in the percentage of firms with no political connections (from $16 \%$ in 1998 to nearly $76 \%$ in 2007 - See Table 1) was mostly because of the large rise in new firms over this period, which was dominated by an increase in the privately-owned, non-affiliated sub-group (see especially Ding et. al., 2016, Table 6).

${ }^{14}$ Note, the sum of the marginal effects for each variable across the three affiliation sub-groups sums to 0 ,
} 
FIGURE 3

Average marginal effect of TFP on probability of political affiliation

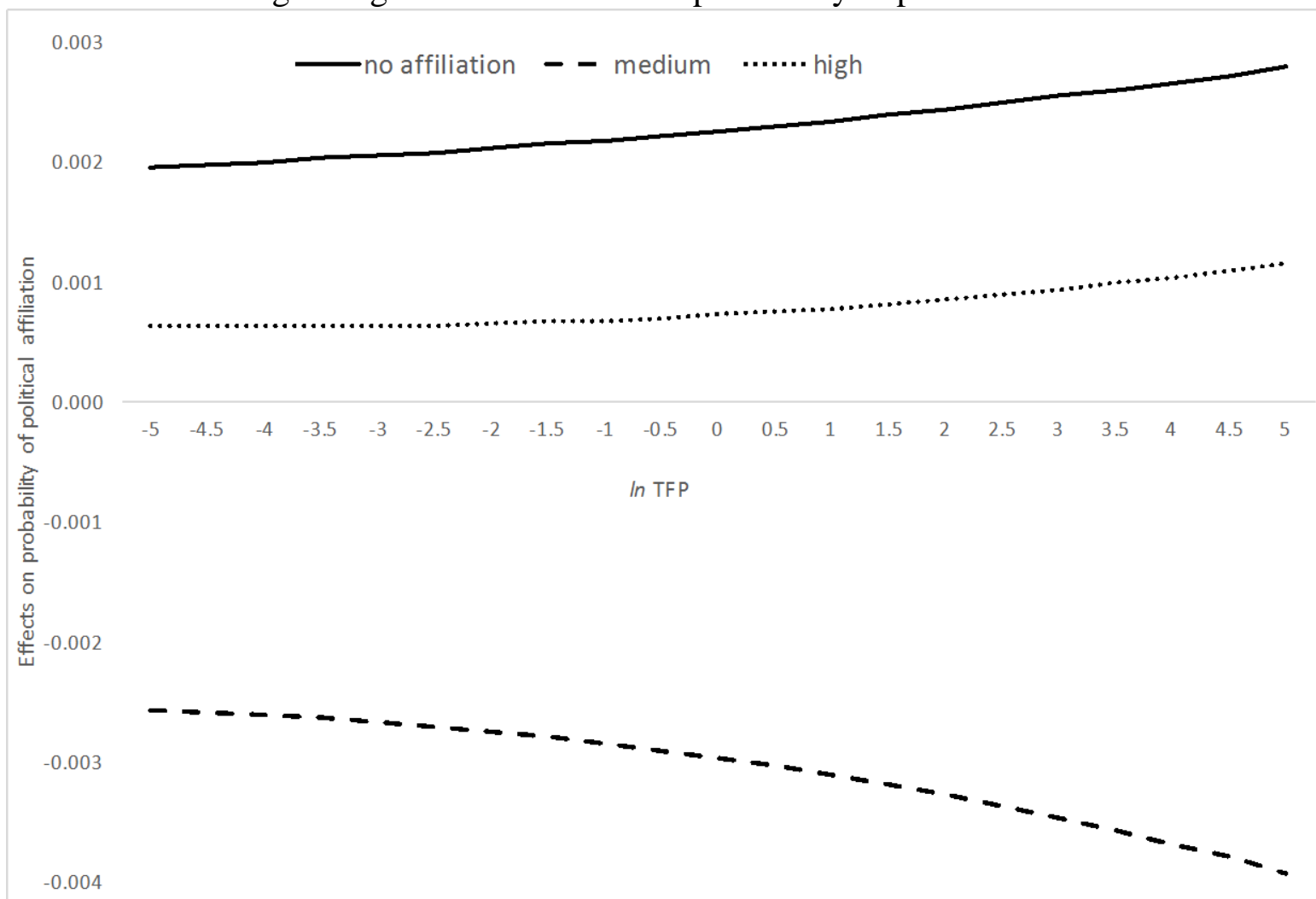

Firms with higher levels of $\ln$ TFP were over three times as likely to belong to the 'no affiliation' sub-group as the 'high affiliation' sub-group, ${ }^{15}$ although both have positive marginal effects (compared to the lower probability of belonging to the 'medium affiliation' sub-group). This indicates that 'high-type' firms, as defined in section 2, are not confined to those with no political connections. Since $\ln$ TFP is a continuous variable, the average marginal effects shown in Table 3 in the Appendix (which show $\partial \hat{p}$ for a small - i.e., unit change in $\ln$ TFP) are not as informative as the impact of a step-change (from 0 to 1 ) associated with categorical variables. Therefore, Figure 3 shows the average marginal effects associated with the range of $\ln$ TFP covering the overwhelming majority of firms; as $\ln$ TFP rises both the probability of belonging to the 'high-' and 'no-' affiliation subs-groups since multinomial logit is estimating the relative probability of a firm belonging to one of these sub-groups.

15 The marginal effect values are 0.00201 compared to 0.00059 , at 5 decimal places. 
increases, although (as stated) the latter is on average three times higher than the 'high' sub-group. The impact of $\ln$ TFP shown in Table 2 and Figure 3 combines all the 'TFP' composite variables included in equation (2); the values of the individual parameter estimates reported in Table A.1 show that the relationship between productivity (and thus 'low' and 'high' type firms) and political connects is more complicated. Linking In TFP with tariff rates (which were declining given China's accession to the WTO) shows that changes in both productivity and tariff rates had almost the same (cet. par.) effect on affiliation; but linking In TFP with new firm entry (as an indicator of liberalisation of the economy) shows that jointly increasing both was associated much more with firms having no political connections relative to strong links with government; this result is strongly supportive of the predictions of the model in section 2.3. Note, however, the full impact of tariffs and new firm entry is as shown in Figures 4 and 5; there is little association with the probability of firms belonging to the 'high affiliation' sub-group, but rather a negative (positive) non-linear link with 'no affiliation' versus 'medium affiliation' as tariff (new firm) rates are increased. The effect of new firm entry is particularly strong, especially for the range of new firm entry that was most prevalent in 1998-2007 (see Table 1). 
FIGURE 4

Average marginal effect of tariffs on probability of political affiliation

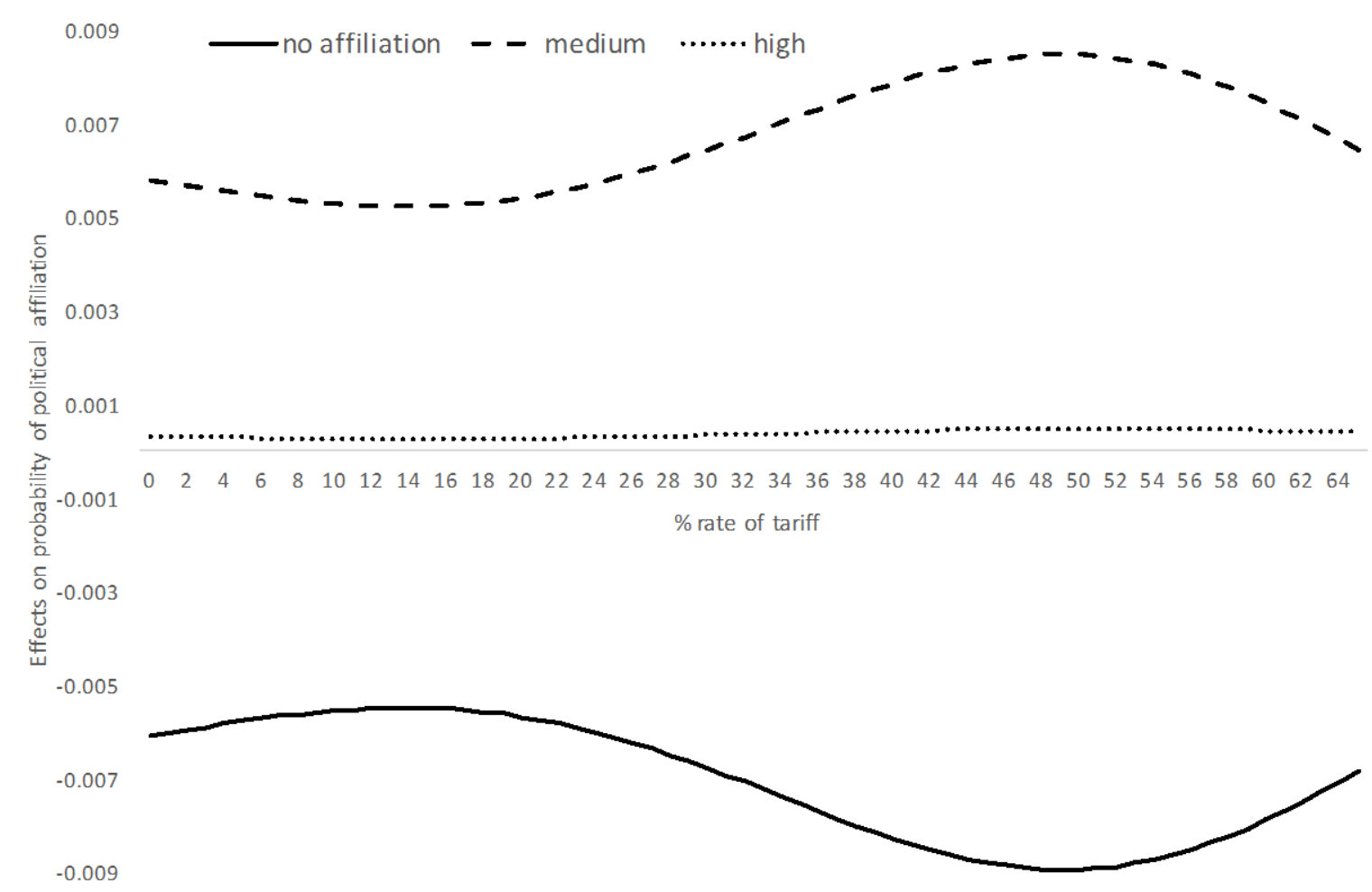

FIGURE 5

Average marginal effects of new firm entry on probability of political affiliation

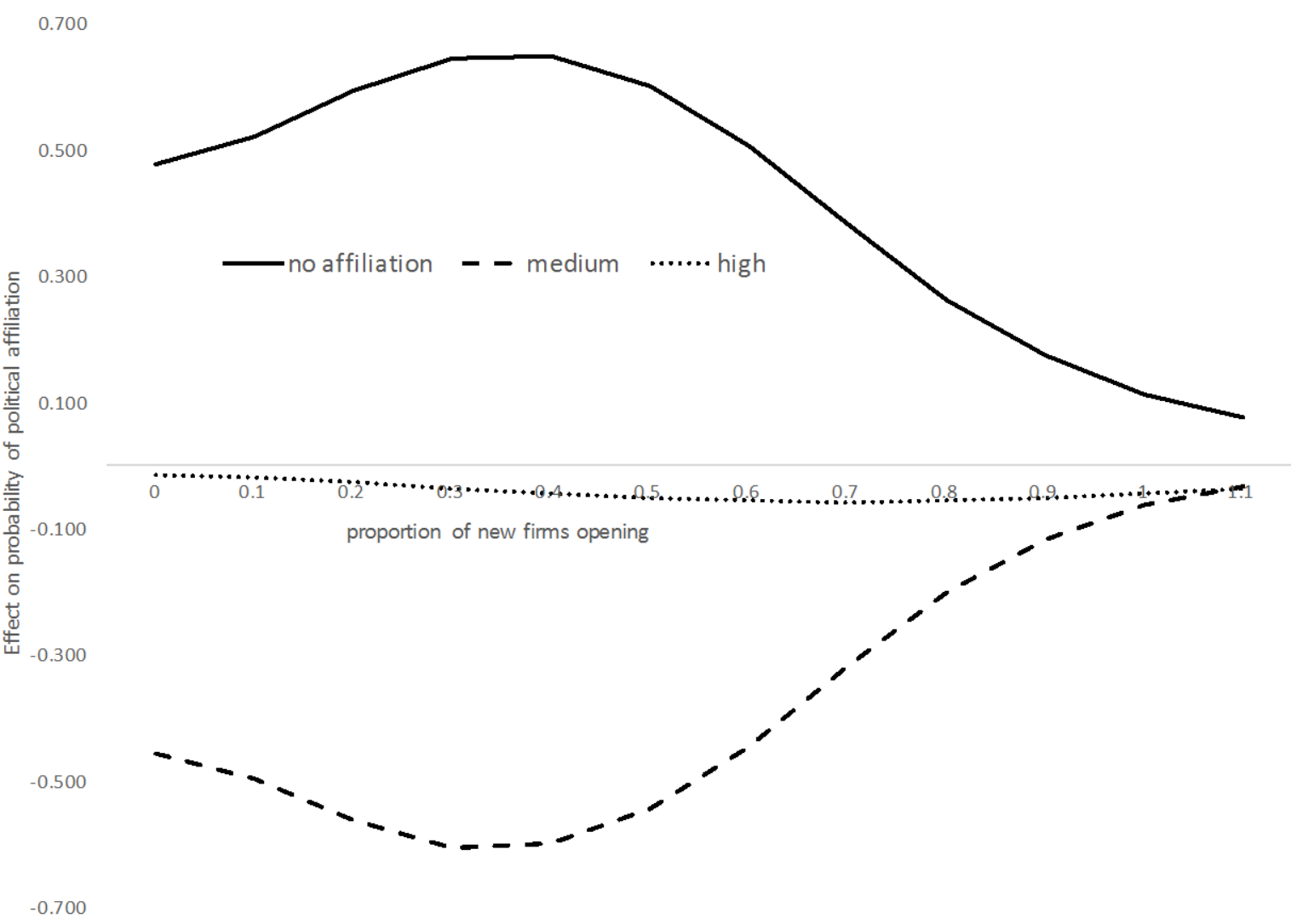


The results shown in Table 4 in the Appendix also show that higher TFP was conjointly more (or as) strongly associated with having central/provincial government political connections (relative to no political links) over time, for state- and foreign-owned firms (including those based in special administrative areas), and collectively-owned firms (although again note the overall marginal effect associated with all but one of these variables is positively linked to a higher probability of belonging to the 'no affiliation' sub-group - see Table 3 in the Appendix). For such firms, having high levels of TFP (and thus being 'high-type' firms) resulted in advantages that were enhanced by strong political links, which suggests that there were significant commercial privileges and/or rewards to such strong political connections (which were largely absent when considering connections with local governments). Such privileges or rewards are also likely to reflect the positive relationship between spending on R\&D and belonging to the strong political links sub-group (Table 3), coupled with the low level of R\&D undertaken by Chinese firms over 1998-2007 (and with no discernible increase in the proportion of firms doing R\&D - see Table 1). There was also little impact of engaging in exporting on 'high affiliation', which again suggests that factors which are usually associated with enhancing productivity were relatively weak in China, and thus did not act to offset the privileges or rewards from strong political connections.

With regard to the impacts on political affiliation of the other variables $\left(X_{\mathrm{it}}\right)$ in equation (2), Table 3 shows that larger and older firms were more likely to (cet. par.) belong to the 'high affiliation' sub-group; being located in the East Coast region, Central or Western China (vis-à-vis North East China) is linked to a lower probability of having no political links; higher levels of spatial agglomeration or diversification, and locating in the largest cities lead to a greater likelihood of having no affiliations, while a higher level of concentration of output in the largest firms has the opposite effect; and having higher fixed 
costs, both negative financial liquidity and higher access to funds are all associated with a lower probability of no political connections. Finally, there are some large differences across industries: relative to the baseline (omitted) industries, being in the tobacco (and to a lesser extent) electric power sectors is associated with strong political affiliations, whist in most other sectors the association is stronger with no affiliation when other attributes (size, ownership, etc.) are controlled for.

\section{SUMMARY AND CONCLUSIONS}

This paper has examined the impact of political control and state ownership on firm performance in China, based on a theoretical model and actual firm-level estimates of total factor productivity for 1998-2007. Our theoretical model is based on the assumptions that firms with higher political affiliations/state ownership retain a higher share of profit and/or face lower production costs (and thus have higher profitability), and that managers receive private rewards from devoting their time to building political connections. As a result of this deviation from profit-maximisation, the managers undertake less than optimal investment in intangible assets to increase innovation; this effect is stronger for firms with lower productivity, and to a lesser extent for firms with strong political links to government (assuming there are tangible and important private benefits from pursuing political links). This reflects the empirical evidence of the lishu relationship being associated with lower productivity (efficiency and innovativeness) but higher profitability. Indeed, as the economy approaches complete liberalisation, the model (and to some extent the empirical evidence) suggests that firms operating with inferior technology are increasingly likely to be state-owned and to have higher rates of closure, and over time to be replaced by more politically independent, technologically more advanced firms.

Data for 1998-2007 showed that political affiliation changed significantly over the period (e.g., 16\% of Chinese firms had no affiliations in 1998, but by 2007 this had risen to 
76\%); in addition, there was a large decline in the importance of SOE's and a rise in firms privately-owned by individuals. Econometric results, based on firm-level TFP for 1998-2007, confirm that, indeed, firms with the highest levels of TFP were more likely to have no political affiliations. When TFP growth is decomposed into the contribution of continuers, entrants and leavers, firms with no political affiliation account for nearly $62 \%$ of overall TFP growth, with most of this contribution coming from new firms entering post-1998 that started life with no lishu links with government. Firms with less than $25 \%$ of shares owned by the state contributed some $74 \%$ of overall TFP growth, again mostly as the result of the entry of new, more productive firms. However, firms with high levels of state ownership were also significant contributors to overall TFP growth, as a result of reallocations of market shares to firms with higher productivity, the closure of inefficient firms, and within-firm improvements in TFP. The results from a multinomial logit model determining the political affiliation sub-group for each firm confirmed that higher TFP overall was associated with no lishu arrangements, and to a lesser extent strong connections to government (but not for connections with local governments). For a minority of firms, having high levels of TFP resulted in advantages that were enhanced by also gaining the benefits associated with strong political links, which suggests that there were significant private privileges and/or rewards to having central government and provincial political connections,

Lastly, since much of the Chinese high growth (in TFP) during 1998-2007 was due to new firm entry with these new privately-owned firms making a choice of mostly no political affiliation, it is possible to surmise that the compositional change from high to low levels of lishu had effectively happened by the end of that period, and thus further 'catch-up' in growth associated with weaker political connections will have been of a lower order of magnitude. This certainly is consistent with what we know about growth in China in the last 5-7 years. 


\section{References}

Aghion, P., R. Burgess, S. Redding, and F. Zilibotti "Entry liberalization and inequality in industrial performance”, Journal of the European Economic Association, 3(2-3), 2005, 291-302.

Berkowitz, D., H. Ma, and S. Nishioka "Recasting the iron rice bowl: the evolution of China's state-owned enterprises”. Mimeo. 2014.

Chan, K. S., V.Q.T. Dang, and I.K.M. Yan “Chinese firms” political connection, ownership, and financial constraints”, Economics Letters, 115, 2012, 164-167.

Chen, S., Z. Sun, S. Tang and D. Wu "Government intervention and investment efficiency: evidence from China”, Journal of Corporate Finance, 17, 2011, 259-271.

Chow, C.K.W., M.K.Y. Fung, K.C.K. Lam, and H. Sami "Investment opportunity set, political connection, and business policies of private enterprises in China”, Review of Quantitative Financial Accounting, 38, 2012, 367-389.

Ding, S., A. Guariglia, and R. Harris “The determinants of productivity in Chinese large and medium-sized industrial firms, 1998-2007”. Journal of Productivity Analysis, 45(2), 2016, 131-155

Du, L., A. Harrison and G. Jefferson "FDI Spillovers and Industrial Policy: The Role of Tariffs and Tax Holidays”, World Development, 64, 2014, 366-383.

Duschl, M., and S.S Peng “The patterns of Chinese firm growth: a conditional estimation approach of the asymmetric exponential power density”. Industrial and Corporate Change, 3, 2015, 539-563.

Ehrlich, I., G. Gallais-Hamonno, Z. Liu, and R. Lutter "Productivity growth and firm ownership: An analytical and empirical investigation”. Journal of Political Economy, 102 (5), 1994, 1006-38. 
Faccio, M. “Politically connected firms”, American Economic Review, 96 (1), 2006, 369-386.

Foster, L., J. Haltiwanger, and C.J. Krizan “Aggregate productivity growth: lessons from microeconomic evidence”, NBER Working Paper No. 6803, 1998

Guo, D., K. Jiang, B.Y. Kim, and C. Xu “Political economy of private firms in China”. Journal of Comparative Economics, 42(2), 2014, 286-303.

Levinsohn, J. and A. Petrin "Estimating production functions using inputs to control for unobservable”, Review of Economic Studies, 70(2), 2003, 317-41.

Li, H., L. Meng, Q. Wang and L.A. Zhou "Political connections, financing and firm performance: evidence from Chinese private firms”, Journal of Development Economics, 87, 2008, 283-299.

Liu, X. and H. Li "Financial constraints and the productivity-survival link: evidence from China’s firm-level data”. Industrial and Corporate Change, first published online: May 9, 2015.doi: 10.1093/icc/dtv020

Peng, M.W., J. Tan, and T. W. Tong “Ownership types and strategic groups in an emerging economy”, Journal of Management Studies, 41, 2004, 1105-1129.

Song, Z., K. Storesletten and F. Zilibotti “Growing like China”, American Economic Review, 101, 2011, 196-233.

Sun, Q., W.H.S. Tong and J. Tong "How does government ownership affect firm performance? Evidence from China’s privatization experience”, Journal of Business Finance \& Accounting, 29, 2002, 1-27.

Tan, J., S. Li, and J. Xia "When iron fist, visible hand, and invisible hand meet: firm-level effects of varying institutional environments in China”, Journal of Business Research, 60, 2007, 786-794.

Wu, W., C. Wu, and O.M. Rui "Ownership and the value of political connections: evidence 
from China”, European Financial Management, 18, 2012, 695-729.

Yu, X., G. Dosi, J. Lei, and A. Nuvolari "Institutional change and productivity growth in China's manufacturing: the microeconomics of knowledge accumulation and ‘creative restructuring””, Industrial and Corporate Change, 24, 2015, 565-602.

Xia, J., S. Li, and C. Long “The transformation of collectively owned enterprises and its outcomes in China, 2001-05”, World Development, 37, 2009, 1651-1662.

Zhou, W. "Political connections and entrepreneurial investment: evidence from China's transition economy”. Journal of Business Venturing, 28, 2013, 299-315. 


\section{APPENDIX}

The Haltiwanger approach

The index of productivity in year $t$ is defined as a geometrically weighted average of individual firm-level productivities. This index and its growth between $t$ and $t-k$ can therefore be written as follows:

$$
\ln P_{t}=\sum_{i} \theta_{i t} \ln P_{i . t} \quad \Delta \ln P_{t}=\ln P_{t}-\ln P_{t .-k}
$$

where $P$ measures productivity and $\theta_{i t}$ is the share of output for firm $i$ in period $t$ for the economy. Thus, productivity growth can be expressed as follows:

$$
\begin{aligned}
& \text { Continuers: within-firm Continuers: Between-firm Continuers: } \\
& \Delta \ln P_{t}=\sum_{i} \theta_{i t-k} \Delta \ln P_{i t}+\quad \sum_{i}\left(\ln P_{i t-k}-\ln P_{t-k}\right) \Delta \theta_{i t}+\quad \sum_{i} \Delta \ln P_{i t} \Delta \theta_{i t}+
\end{aligned}
$$

Entering firms $\quad$ Exiting firms

$$
\sum_{i} \theta_{i t}\left(\ln P_{i t}-\ln P_{t-k}\right)-\quad \sum_{i} \theta_{i t-k}\left(\ln P_{i t-k}-\ln P_{t-k}\right)
$$


TABLE 1

Descriptive statistics for variables used in determining political affiliation, China 1998-2007

\begin{tabular}{|c|c|c|c|c|c|}
\hline \multirow[t]{2}{*}{ Variables } & \multirow[t]{2}{*}{ Definition } & \multicolumn{2}{|c|}{1998} & \multicolumn{2}{|c|}{2007} \\
\hline & & Mean & SD & Mean & SD \\
\hline No affiliation & No political affiliations & 0.155 & 0.362 & 0.758 & 0.428 \\
\hline Medium affiliation & $\begin{array}{l}\text { Medium political affiliation with local governments (e.g., city, district, county, prefecture, } \\
\text { township and village) - the benchmark group in the multinomial model estimated }\end{array}$ & 0.724 & 0.447 & 0.210 & 0.407 \\
\hline High affiliation & High political affiliation with central or provincial governments & 0.121 & 0.326 & 0.031 & 0.174 \\
\hline In TFP & Obtained from Ding et. al. (2016) & -2.730 & 1.554 & -2.102 & 1.171 \\
\hline Employees $300+$ & A dummy variable $=1$ if firm employees $300+$ employees & 0.302 & 0.459 & 0.147 & 0.354 \\
\hline In firm age & In firm age (based on year-of-birth) & 2.443 & 0.923 & 2.092 & 0.820 \\
\hline Foreign-owned & Dummy variable $=1$ if proportion of capital owned that is foreign-owned $>=0.5^{\mathrm{a}}$ & 0.049 & 0.216 & 0.070 & 0.255 \\
\hline SOE & Dummy variable $=1$ if proportion of capital owned by state $>=0.5^{\mathrm{a}}$ & 0.317 & 0.465 & 0.037 & 0.189 \\
\hline HK/Macau/Taiwan-owned & Dummy variable $=1$ if proportion of capital owned that is HK/Macau/Taiwan-owned $>=0.5^{\mathrm{a}}$ & 0.059 & 0.236 & 0.070 & 0.254 \\
\hline Collective-owned & Dummy variable $=1$ if proportion of capital owned by collectives $>=0.5^{a}$ & 0.300 & 0.458 & 0.047 & 0.212 \\
\hline Exporter & A dummy variable for firms that export & 0.251 & 0.434 & 0.233 & 0.423 \\
\hline R\&D dummy & Dummy variable $=1$ if firm undertook any spending on $R \& D$ & 0.101 & 0.302 & 0.100 & 0.300 \\
\hline In agglomeration & $\begin{array}{l}\text { In \% of industry output (2-digit SIC) located in each province in which firm is located - } \\
\text { MAR-spillovers }\end{array}$ & 1.621 & 1.125 & 1.845 & 1.101 \\
\hline In Herfindahl & In Herfindahl index of industrial concentration (by 2-digit SIC) & -6.069 & 1.075 & -6.605 & 1.060 \\
\hline In diversification & $\begin{array}{l}\text { In proportion of 3-digit industries (maximum 226) located in (208) city areas in which firm is } \\
\text { located - Jacobian spillovers }\end{array}$ & -0.469 & 0.400 & -0.646 & 0.325 \\
\hline In fixed costs & In selling \& distribution costs as $\%$ of sales & 1.164 & 0.926 & 0.968 & 0.813 \\
\hline Neg_liquid & Dummy variable $=1$ if ratio of (current assets - current liabilities) to total assets $\leq 0$ & 0.485 & 0.500 & 0.385 & 0.487 \\
\hline In liquidity & In [1 +ratio of (current assets - current liabilities) to total assets] & 0.100 & 0.142 & 0.135 & 0.160 \\
\hline City200 & Dummy = 1 for firm located in top 200 cities based on population size & 0.268 & 0.443 & 0.873 & 0.333 \\
\hline Tariff rate (fob final goods) & $\begin{array}{l}\text { Percentage rate of ad valorem tariff (fob final goods) for } 44 \text { industries (source: WITS, } \\
\text { Worldbank) }\end{array}$ & 16.570 & 8.166 & 9.241 & 4.460 \\
\hline New firm entry & No. new firms $\div$ no. existing firm for each 2 -digit industry SIC/province/year & 0.042 & 0.022 & 0.022 & 0.024 \\
\hline Western China & $\begin{array}{l}\text { Dummy = } 1 \text { for firm located in Xinjing, Tibet, Gansu, Qinghai, Sichuan, Chongqing, Yunnan, } \\
\text { Guizhou, Guangxi, Inner Mongolia }\end{array}$ & 0.136 & 0.342 & 0.104 & 0.305 \\
\hline East Coast & $\begin{array}{l}\text { Dummy = } 1 \text { for firm located in Guangdong, Fujian, Zhejiang, Jiangsu, Shandong, Hainan, } \\
\text { Hebrei, Beijing, Tianjin, Shanghai }\end{array}$ & 0.602 & 0.490 & 0.676 & 0.468 \\
\hline Central China & Dummy = 1 for firm located in Hunan, Jiangxi, Hubei, Anhui, Henan, Shanxi & 0.194 & 0.395 & 0.151 & 0.358 \\
\hline $\mathrm{N}$ & No. of observations & 106.8 & sand & 279.2 & Isand \\
\hline
\end{tabular}

${ }^{\mathrm{a}}$ For firms with $<50 \%$ share ownership in a particularly category, they were assigned to the largest ownership sub-group 
TABLE 2

Firm-level TFP growth (average per annum) by political affiliation and State Ownership, 1998-2007, China

\begin{tabular}{|c|c|c|c|c|c|c|c|}
\hline & \multirow{2}{*}{$\frac{\text { TFP growth (\% p.a.) }}{\text { Actual }}$} & \multicolumn{4}{|c|}{ Decomposition of (weighted) TFP growth } & \multicolumn{2}{|c|}{ Output share (\%) } \\
\hline & & $\begin{array}{l}\text { Within firm } \\
\text { (2) }\end{array}$ & $\begin{array}{l}\text { Between firm } \\
\text { (3) }\end{array}$ & $\begin{array}{c}\text { Enterers } \\
\text { (4) }\end{array}$ & $\begin{array}{c}\text { Exitors } \\
\text { (5) }\end{array}$ & $\begin{array}{c}1998 \\
(6)\end{array}$ & $\begin{array}{r}2007 \\
(7)\end{array}$ \\
\hline No political affiliation & 5.94 & 0.28 & -0.01 & 6.20 & -0.53 & 12.9 & 55.4 \\
\hline Medium level affiliation $^{a}$ & -0.51 & 0.43 & 0.31 & 1.25 & -2.50 & 49.5 & 21.4 \\
\hline High level affiliation ${ }^{\mathrm{b}}$ & 4.20 & 1.43 & 2.07 & -0.42 & 1.13 & 37.6 & 23.2 \\
\hline All firms & 9.63 & 2.12 & 2.41 & 7.03 & -1.93 & 100 & 100 \\
\hline State ownership $<25 \%$ & 7.12 & 1.33 & 1.25 & 7.11 & -2.57 & 53.5 & 83.1 \\
\hline State ownership $25-50 \%$ & 0.04 & 0.07 & 0.06 & 0.04 & -0.13 & 4.7 & 2.2 \\
\hline State ownership $>50 \%$ & 2.47 & 0.68 & 1.11 & -0.12 & 0.79 & 41.9 & 14.6 \\
\hline All firms & 9.63 & 2.12 & 2.41 & 7.03 & -1.93 & 100 & 100 \\
\hline
\end{tabular}

\footnotetext{
${ }^{a}$ Those firms reporting lishu links with government below the level of the province (e.g., cities, local government, etc.)

${ }^{\mathrm{b}}$ Those firms reporting lishu links with government at province or central government level.
} 
TABLE 3

Average marginal effects of extent of political affiliation, 1998-2007

\begin{tabular}{|c|c|c|c|c|c|c|}
\hline & $\frac{\partial \frac{\text { No affil }}{\hat{p}}}{\partial x}$ & z-value & $\frac{\partial \hat{p}}{\partial x}{ }^{\frac{\text { affilia }}{\text { med }}}$ & $\frac{\mathrm{um}}{\text { tion }}$ & $\begin{array}{l}\frac{\partial \hat{p}}{\partial \hat{p}} \\
\frac{\partial x h}{a f f}\end{array}$ & $\begin{array}{l}\text { iation } \\
\text { z-value } \\
\end{array}$ \\
\hline Medium affiliation $_{\mathrm{t}-1}$ & -0.647 & -593.2 & 0.654 & 602.3 & -0.007 & -22.0 \\
\hline High affliation $_{\mathrm{t}-1}$ & -0.722 & -283.4 & -0.089 & -55.1 & 0.811 & 278.4 \\
\hline In TFP & 0.002 & 4.6 & -0.003 & -6.0 & 0.001 & 5.4 \\
\hline Tariff rate (fob final goods) & -0.005 & -45.5 & 0.005 & 43.5 & 0.000 & 7.1 \\
\hline New firm entry & 0.479 & 46.2 & -0.461 & -43.9 & -0.018 & -5.5 \\
\hline$t$ & 0.006 & 35.7 & -0.006 & -34.3 & -0.000 & -4.5 \\
\hline SOE & -0.139 & -74.3 & 0.124 & 69.5 & 0.015 & 29.6 \\
\hline foreign-owned & 0.001 & 1.5 & -0.001 & -1.2 & -0.000 & -0.8 \\
\hline HK/Macau/Taiwan-owned & 0.013 & 13.2 & -0.010 & -10.0 & -0.003 & -6.4 \\
\hline Collective-owned & -0.099 & -100.5 & 0.101 & 100.6 & -0.001 & -4.7 \\
\hline Employees 300+ & -0.015 & -24.4 & 0.012 & 19.5 & 0.003 & 16.3 \\
\hline In age & -0.015 & -47.6 & 0.014 & 43.9 & 0.001 & 12.8 \\
\hline Exporter & 0.007 & 12.1 & -0.007 & -12.3 & 0.000 & 0.9 \\
\hline R\&D dummy & 0.001 & 1.9 & -0.004 & -5.8 & 0.003 & 13.6 \\
\hline Western China & -0.020 & -16.7 & 0.020 & 16.5 & 0.000 & 0.8 \\
\hline East Coast & -0.003 & -2.4 & 0.001 & 1.1 & 0.001 & 4.5 \\
\hline Central China & -0.018 & -16.3 & 0.019 & 17.3 & -0.001 & -3.5 \\
\hline City 200 & 0.007 & 10.2 & -0.007 & -10.4 & 0.000 & 0.4 \\
\hline In Agglomeration & 0.005 & 17.5 & -0.003 & -10.2 & -0.002 & -27.1 \\
\hline In Herfindahl & -0.024 & -23.7 & 0.024 & 23.6 & 0.000 & 0.2 \\
\hline In Diversification & 0.019 & 20.8 & -0.022 & -23.5 & 0.002 & 10.1 \\
\hline In Fixed costs & -0.002 & -7.4 & 0.002 & 6.6 & 0.000 & 3.0 \\
\hline Neg_liquid & -0.002 & -2.7 & 0.002 & 2.9 & 0.000 & -0.6 \\
\hline In liquidity & -0.004 & -1.9 & 0.003 & 1.7 & 0.000 & 0.6 \\
\hline Food production & 0.114 & 33.9 & -0.106 & -31.5 & -0.008 & -8.2 \\
\hline Tobacco & -0.005 & -2.3 & -0.295 & -23.2 & 0.301 & 23.5 \\
\hline Textiles & 0.064 & 24.1 & -0.055 & -20.7 & -0.009 & -10.5 \\
\hline Apparel \& footwear & 0.086 & 28.4 & -0.076 & -25.2 & -0.010 & -10.2 \\
\hline Leather goods & 0.108 & 33.4 & -0.095 & -29.3 & -0.013 & -11.2 \\
\hline Timber & 0.042 & 17.0 & -0.038 & -15.3 & -0.004 & -5.0 \\
\hline Furniture & 0.058 & 19.5 & -0.052 & -17.4 & -0.006 & -5.7 \\
\hline Papermaking & 0.054 & 20.3 & -0.046 & -17.3 & -0.008 & -9.6 \\
\hline Printing & 0.019 & 6.8 & -0.016 & -6.0 & -0.002 & -3.0 \\
\hline Cultural & 0.003 & 1.0 & 0.002 & 0.7 & -0.005 & -5.1 \\
\hline Petroleum processing & 0.086 & 23.1 & -0.085 & -22.8 & -0.001 & -0.8 \\
\hline Basic chemicals & 0.042 & 19.9 & -0.038 & -18.0 & -0.004 & -6.4 \\
\hline Medical instruments & 0.039 & 16.8 & -0.037 & -15.7 & -0.002 & -3.6 \\
\hline Chemical fibres & 0.096 & 23.3 & -0.091 & -22.0 & -0.005 & -3.9 \\
\hline
\end{tabular}




\begin{tabular}{lrrrrrr} 
Rubber & 0.102 & 30.4 & -0.094 & -28.1 & -0.008 & -7.4 \\
Plastics & 0.035 & 12.8 & -0.028 & -10.1 & -0.007 & -8.8 \\
Nonmetal products & 0.033 & 11.2 & -0.026 & -9.1 & -0.006 & -7.4 \\
Metal products & 0.051 & 21.1 & -0.047 & -19.4 & -0.004 & -6.0 \\
Machinery \& equipment & 0.023 & 9.1 & -0.019 & -7.6 & -0.004 & -5.4 \\
Transport equipment & 0.105 & 35.9 & -0.102 & -34.8 & -0.003 & -3.3 \\
Measuring instruments & 0.092 & 29.6 & -0.089 & -28.7 & -0.003 & -3.3 \\
Other manufacturing & 0.085 & 29.2 & -0.078 & -26.8 & -0.007 & -7.6 \\
Electric power & 0.005 & 6.9 & -0.039 & -12.5 & 0.034 & 10.7 \\
Gas production & 0.043 & 6.8 & -0.039 & -6.3 & -0.003 & -2.3 \\
Water production & 0.003 & 0.6 & -0.002 & -0.4 & -0.001 & -1.0 \\
Coal mining & 0.043 & 15.0 & -0.041 & -14.6 & -0.001 & -1.7 \\
Petroleum \& gas extraction & 0.110 & 9.9 & -0.118 & -10.6 & 0.008 & 4.0 \\
\hline
\end{tabular}


The multinomial logit model results

TABLE 4

Multinomial logit of extent of political affiliation in Chinese firms, 1998-2007

\begin{tabular}{|c|c|c|c|c|}
\hline & \multicolumn{2}{|c|}{ No affiliation } & \multicolumn{2}{|c|}{ High affiliation } \\
\hline & $\hat{\beta}$ & $z$-value ${ }^{a}$ & $\hat{\beta}$ & z-value ${ }^{a}$ \\
\hline Medium affiliation $_{\mathrm{t}-1}$ & -4.066 & -576.36 & -2.446 & -74.32 \\
\hline High affliation $_{\mathrm{t}-1}$ & -2.050 & -64.94 & 5.837 & 178.52 \\
\hline In TFP & 0.135 & 7.84 & 0.062 & 1.48 \\
\hline In TFP $x$ Tariff rate (fob final goods) & -0.004 & -4.23 & -0.004 & -1.95 \\
\hline In TFP x New firm entry & -0.474 & -4.36 & -1.144 & -3.45 \\
\hline In TFP $\times t$ & -0.007 & -5.14 & 0.011 & 3.02 \\
\hline In TFP $\times$ SOE & 0.118 & 10.30 & 0.114 & 5.71 \\
\hline In TFP $x$ foreign-owned & -0.019 & -1.47 & 0.044 & 1.02 \\
\hline In TFP x HK/Macau/Taiwan -owned & 0.020 & 1.71 & 0.048 & 0.96 \\
\hline In TFP x Collective-owned & -0.081 & -8.98 & 0.020 & 0.66 \\
\hline Employees 300+ & -0.198 & -22.50 & 0.350 & 13.49 \\
\hline$t$ & 0.069 & 17.48 & 0.034 & 2.68 \\
\hline In age & -0.215 & -46.43 & 0.080 & 5.83 \\
\hline foreign-owned & -0.022 & -0.75 & 0.090 & 0.86 \\
\hline SOE & -1.411 & -37.70 & 1.002 & 15.42 \\
\hline HK/Macau/Taiwan-owned & 0.210 & 7.95 & -0.202 & -1.68 \\
\hline Collective-owned & -1.484 & -62.60 & -0.660 & -7.75 \\
\hline New firm entry & 5.757 & 19.28 & -2.720 & -2.66 \\
\hline Tariff rate (fob final goods) & -0.083 & -33.87 & -0.006 & -0.82 \\
\hline Exporter & 0.105 & 12.36 & 0.072 & 2.49 \\
\hline R\&D dummy & 0.040 & 3.71 & 0.437 & 14.71 \\
\hline In Agglomeration & 0.062 & 14.37 & -0.298 & -25.20 \\
\hline In Herfindahl & -0.353 & -23.88 & -0.147 & -3.34 \\
\hline In Diversification & 0.297 & 22.14 & 0.484 & 13.96 \\
\hline In Fixed costs & -0.029 & -7.12 & 0.023 & 1.91 \\
\hline In liquidity & -0.054 & -1.83 & 0.036 & 0.36 \\
\hline Neg_liquid & -0.026 & -2.83 & -0.029 & -0.97 \\
\hline Western China & 0.103 & 10.43 & -0.091 & -1.85 \\
\hline East Coast & -0.296 & -16.73 & 0.194 & 4.18 \\
\hline Central China & -0.029 & -1.85 & -0.291 & -5.93 \\
\hline City 200 & -0.272 & -16.90 & 0.056 & 1.87 \\
\hline \multicolumn{5}{|l|}{ Industry } \\
\hline Food production & 1.603 & 33.19 & -0.516 & -3.41 \\
\hline Tobacco & 1.123 & 3.17 & 4.334 & 23.44 \\
\hline Textiles & 0.871 & 22.85 & -0.936 & -7.39 \\
\hline Apparel \& footwear & 1.183 & 27.31 & -0.929 & -6.45 \\
\hline
\end{tabular}




\begin{tabular}{|c|c|c|c|c|}
\hline Leather goods & 1.485 & 32.05 & -1.277 & -7.37 \\
\hline Timber & 0.578 & 16.48 & -0.357 & -2.87 \\
\hline Furniture & 0.806 & 18.84 & -0.504 & -3.31 \\
\hline Papermaking & 0.731 & 19.22 & -0.869 & -6.96 \\
\hline Printing & 0.256 & 6.51 & -0.216 & -1.97 \\
\hline Cultural & 0.008 & 0.20 & -0.727 & -5.04 \\
\hline Petroleum processing & 1.248 & 23.19 & 0.418 & 2.51 \\
\hline Basic chemicals & 0.581 & 19.27 & -0.345 & -3.64 \\
\hline Medical instruments & 0.549 & 16.47 & -0.113 & -1.13 \\
\hline Chemical fibres & 1.364 & 22.98 & -0.155 & -0.78 \\
\hline Rubber & 1.426 & 29.73 & -0.528 & -3.35 \\
\hline Plastics & 0.464 & 11.74 & -0.893 & -7.07 \\
\hline Nonmetal products & 0.435 & 10.36 & -0.759 & -5.88 \\
\hline Metal products & 0.709 & 20.55 & -0.307 & -2.94 \\
\hline Machinery \& equipment & 0.303 & 8.52 & -0.443 & -4.09 \\
\hline Transport equipment & 1.510 & 35.80 & 0.253 & 1.98 \\
\hline Measuring instruments & 1.317 & 29.47 & 0.161 & 1.23 \\
\hline Other manufacturing & 1.189 & 28.42 & -0.477 & -3.56 \\
\hline Electric power & 1.036 & 8.94 & 0.530 & 11.55 \\
\hline Gas production & 0.598 & 6.59 & -0.252 & -1.12 \\
\hline Water production & 0.038 & 0.50 & -0.171 & -0.95 \\
\hline Coal mining & 0.611 & 14.96 & 0.062 & 0.49 \\
\hline Petroleum \& gas extraction & 1.644 & 10.26 & 1.971 & 6.18 \\
\hline Intercept & 0.883 & 8.66 & -3.063 & -9.97 \\
\hline Pseudo- $R^{2}$ & & 0.69 & & \\
\hline Log Likelihood & & 384.2 & & \\
\hline $\mathrm{N}$ & & 4,800 & & \\
\hline
\end{tabular}

${ }^{a}$ Based on robust standard errors. These are not substantively altered when standard errors are based on clustering (using industry and/or industry by province as the cluster variable). 